Hubel, Brian A.; Letter, Joseph V.; Goodhue, Mark; Lee, Landris T.

A Practical Approach to Assess Combined Levee Erosion, Seepage, and Slope Stability Failure Modes

Verfügbar unter / Available at:

https://hdl.handle.net/20.500.11970/100301

Vorgeschlagene Zitierweise / Suggested citation:

Hubel, Brian A.; Letter, Joseph V.; Goodhue, Mark; Lee, Landris T. (2010): A Practical Approach to Assess Combined Levee Erosion, Seepage, and Slope Stability Failure Modes. In: Burns, Susan E.; Bhatia, Shobha K.; Avila, Catherine M. C.; Hunt, Beatrice E. (Hg.): Proceedings 5th International Conference on Scour and Erosion (ICSE-5), November 7-10, 2010, San Francisco, USA. Reston, Va.: American Society of Civil Engineers. S. 273-282. 


\title{
A Practical Approach to Assess Combined Levee Erosion, Seepage, and Slope Stability Failure Modes
}

\author{
Brian A. Hubel, P.E., G.E. ${ }^{1}$, Joseph V. Letter, Jr., Ph.D., P.E. ${ }^{2}$, Marc Goodhue, P.E. ${ }^{3}$, \\ Landris T. Lee, P.E. ${ }^{4}$
}

${ }^{1}$ Senior Civil Engineer, U.S. Army Corps of Engineer San Francisco District GeoSciences Section, 1455 Market Street, San Francisco, CA 94103

${ }^{2}$ Research Hydraulic Engineer, U.S. Army Engineer Research and Development Center, 3909 Halls Ferry Rd., Vicksburg, MS 39180

${ }^{3}$ Geo-Sciences Section Chief, U.S. Army Corps of Engineer San Francisco District Geo-Sciences Section, 1455 Market Street, San Francisco, CA 94103

${ }^{4}$ Research Civil Engineer, U.S. Army Engineer Research and Development Center, 3909 Halls Ferry Rd., Vicksburg, MS 39180

\begin{abstract}
Probability of unsatisfactory performance (system response) curves were developed for seepage, slope stability, and erosion potential failure modes during a flood reduction feasibility study. The erosion-induced breaching failure mode included water-side storm surge and wave runup with or without concurrent land-side overtopping. Response curves were developed for landside and waterside slope stability and landside seepage failure modes for various hydrostatic water loads. This paper illustrates an approach for evaluating the overall system response considering levee seepage, stability, and erosion response under various hydrodynamic loading and geomorphological uncertainties.
\end{abstract}

\section{INTRODUCTION}

Probabilistic methods to evaluate the geotechnical performance of earthen levees are required to better understand economic and life-safety risks of earthen levee structures for engineers, managers, planners, and the general public. Additionally, proposed legislation will require that in order for levees and floodwall structures to be considered to provide flood reduction benefits by the Federal Emergency Management Agency (FEMA) and the National Flood Insurance Program (NFIP) levees and floodwalls must meet specific reliability performance criteria (FEMA, 2006). Although methods for statistical evaluation of the hydraulic aspects have been widely used, the overall system response is rarely been considered in engineering analyses. Hesitance to apply probabilistic methods by geotechnical practitioners in levee analyses is partially due to:

a. unfamiliarity by geotechnical engineers with probabilistic analyses,

b. a general lack of guidance for incorporating both aleatory and epistemic geotechnical uncertainty,

c. models that have not been calibrated to real world performance, and

d. difficulty in presenting probabilities of unsatisfactory levee performance (Duncan, 2000, Christian et al. 1994). 
The overall performance of an earthen levee system is highly sensitive to the geotechnical performance of the levee. USACE guidance for project feasibility studies requires that existing systems be holistically evaluated using probabilistic methods to estimate annual damages over a standard project life cycle (USACE 2006). Damage estimates (risk) for a given event frequency are simplified as shown .

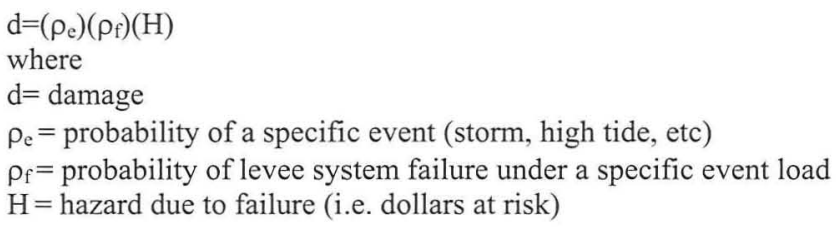

Damage (d) is integrated over all possible events to find a total estimate of annual damages. Uncertainty of each event and of performance can also be evaluated to estimate a confidence bounds of the damage estimates. Significant analysis is required to define events, parameters and their uncertainties and the relationship between system failure and the loading. Monte-Carlo methodology is a suitable and easy approach to integrate many uncertain parameters with varying distributions, provided the computational power is available. Figure 1 illustrates a holistic approach to evaluating levee system response using a Monte-Carlo methodology.

A practical approach to define the geotechnical inputs of levee performance (erosion, stability, and seepage) is presented in the sections below. The results are curves and tables that relate the probability of unsatisfactory performance to defined loading. Although the performance of the different performance modes (erosion, slope stability and seepage) may be related, convenient, comprehensive models are not available to practicing engineers. The failure modes are treated as independent performance modes for ease of application. For this discussion the erosion modes are "dynamic" failure modes, and specifically consider the time-dependant erosion progression. For stability and seepage, a practical approach is to select index points along a levee reach and evaluate under assumed steady state, static water level conditions.

The term, "Probability of Unsatisfactory Performance" $\left(\mathrm{P}_{\mathrm{u}}\right)$ was chosen to describe the probability that specific levee states are less than a defined limit state. For seepage analysis, the limit state is defined as a critical seepage gradient, for stability it is defined as a slope stability slip surface that extends half way through the levee crest having a factor of safety less than one, and for erosion $\mathrm{P}_{\mathrm{u}}$ was defined as the probability of a levee breach occurrence. Although treated as a probability of failure in damage estimates, in many situations the levee states may indicate failure compared to the critical limit state but the levees may not fail in a way that leads to breach and uncontrolled flooding. For this reason, Probability of Unsatisfactory Performance is preferred terminology. Future research into calibrated failure models and event-tree type analysis may more accurately predict levee breaching and flooding. 


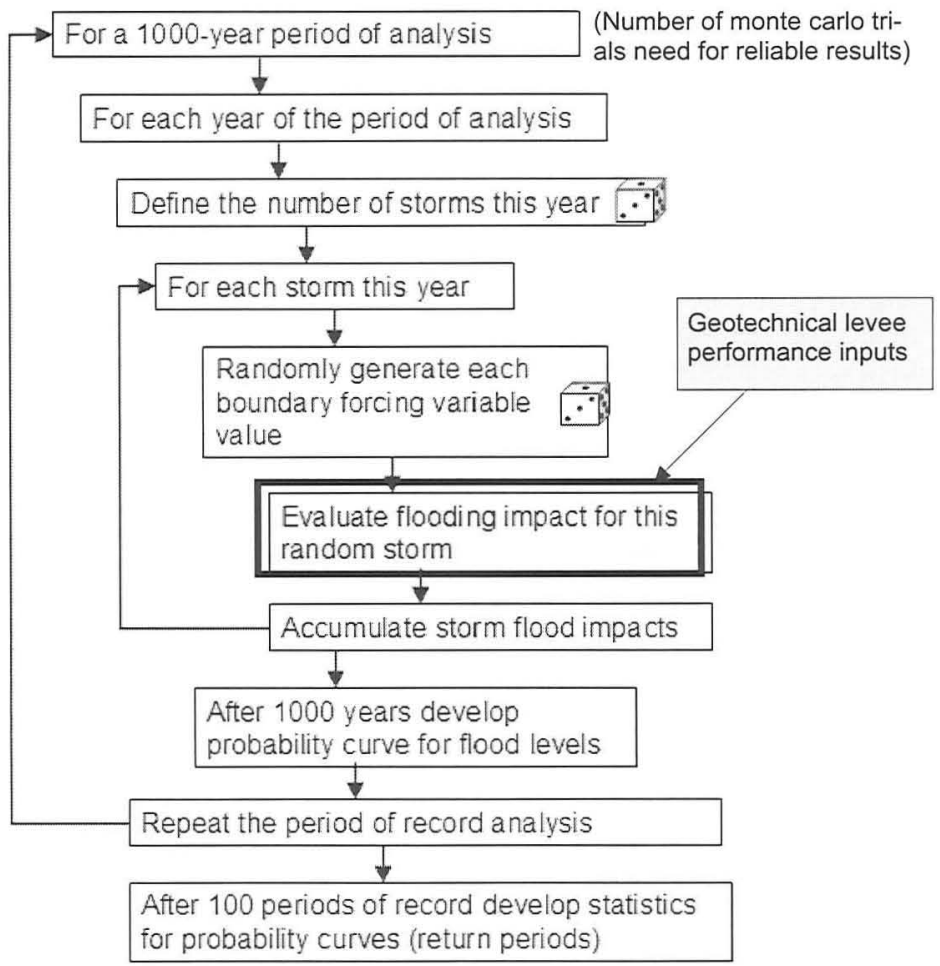

Figure 1. Overall Analysis Structure for a Monte Carlo Analysis

\section{SLOPE STABILITY AND SEEPAGE PROBABILITY OF UNSATISFATORY PERFORMANCE}

This example illustrates how levee performance curves may be developed in general accordance with the guidance provided in USACE ETL 1110-2-556 Evaluating the Reliability of Existing Levees (USACE 1999). The purpose of levee performance evaluation is to evaluate the geotechnical slope stability and seepage performance of the study area levees for economic cost/benefit analysis. The resulting performance curves are intended to be used as an input, along with hydraulic, hydrologic, coastal, and economic inputs, to determine the annual economic damages (See Figure 1). The performance levee segments are presented as a probability of unsatisfactory levee performance as a function of still water elevation.

\section{Notes Regarding Index Point Selection and Spatial Variability}

Probabilistic analysis in geotechnical engineering applications is not a new concept. Many have illustrated how these concepts are relatively easily applied to problems such as retaining walls, slope stability, and foundation design (Duncan, other references). Most of these problems are relatively small, spatially, when compared 
to many levee systems that often extend many miles. Research into spatial variability and spatial-correlation functions may one day help solve problems dealing with long geotechnical structures, these methods are not mature or easily applied in engineering practice.

Levee systems are commonly compared to links in a chain, (ie the levee is only as good as it's weakest link). Some have proposed that the weak point in the levee should be identified and evaluated to determine the overall system probability of unsatisfactory performance (Wolff, 1994). These ideas have validity, but the question remains, "How do we know we have identified the weak link?" There are weakness in this methodology, however, with a competent engineering it is reasoned that engineering judgment will guide the analyses such that the weak points of a levee system are identified. Practitioners, at a minimum should:

- Review the project geology and project construction history. Be sure to explore each geologic formation and each different construction history.

- Review past failures, and explore known failure/problem areas.

- Review geomorphology and explore conditions that might result in differing geotechnical conditions in the levee foundation.

- Understand the flood basin in terms of internal topography and economic impact areas to be sure chosen index points do not rule out the possibility of flooding in other areas of the basin.

- Understand the levee geometry.

- Have local experience with the geologic and geotechnical conditions expected at the project site.

- Consider and perform geophysical studies as appropriate

Figure 2 illustrates a practical approach to identifying the weak link of a levee. These steps are:

1) Identify if material properties appear uniformly distributed across the project space. Visually, this may be done by plotting all of the subsurface information on a single plot to look for outlier locations spatially.

2) For locations where subsurface conditions do not fit the general material distribution these locations should be evaluated discretely using the location specific geometry (surface and subsurface layering).

3) The weak geometry (surface and subsurface layering) with distributed soil properties should be used to calculate probability of unsatisfactory performance when the overall soil property distribution does not show clearly weaker locations.

4) The less reliable of steps 2 and 3 is used to estimate the system probability of unsatisfactory performance. 


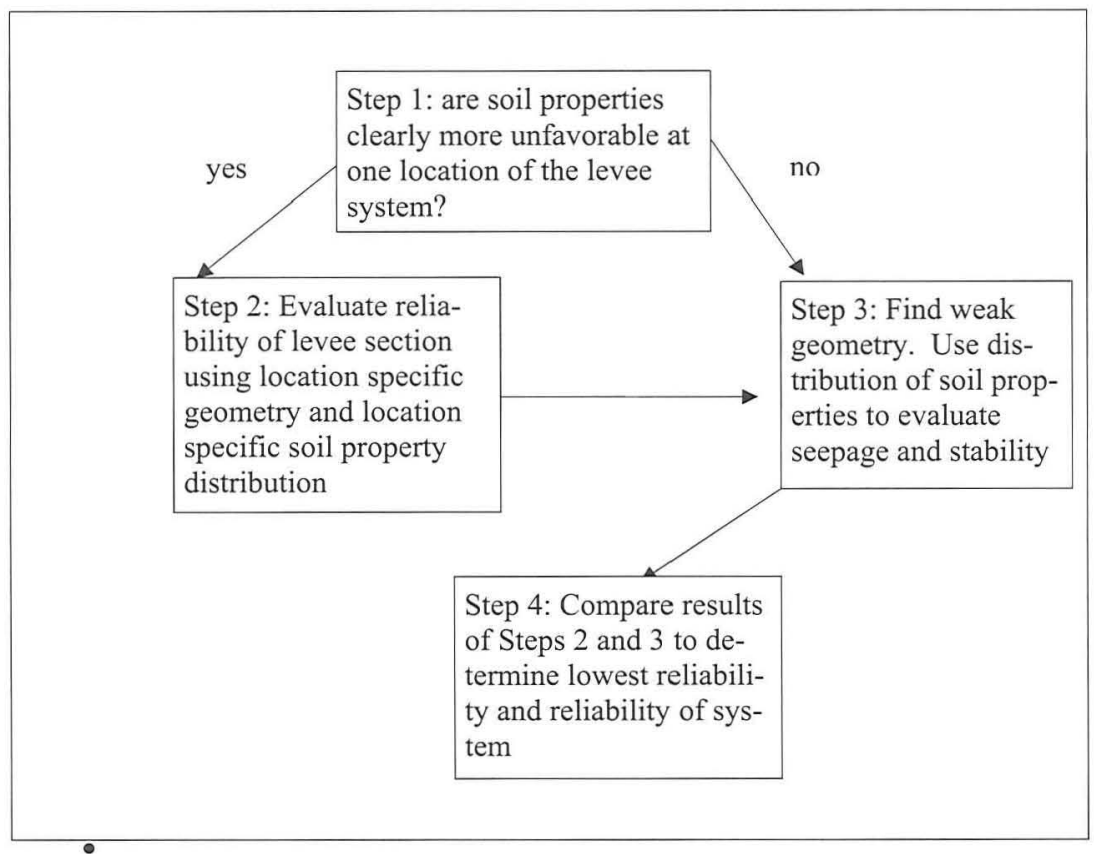

Figure 2: Selecting Index Points for Evaluation of Levee System Stability and Seepage

\section{Slope Stability}

Slope stability analyses may be performed using limit equilibrium methods, such as the popular computer software Slope/W by Geoslope International. Soil properties are input for each layer with a defined parameter distribution for Monte Carlo slope stability trials. Careful definition of what constitutes unsatisfactory performance is required. For this example it was judged that slip surfaces that extend atleast $1 / 2$ way through the levee crest have the potential to cause unsatisfactory performance if the factor of safety is less than 1.0. In general, shallower slip surfaces often have lower factors of safety and surfaces extending further into the levee have higher factors of safety. Searches for the potential surfaces were performed by fixing the surface at the midpoint of the levee crest, and allowing a range of potential exit points, to find the surface with the lowest factor of safety. Figure 3 illustrates the slip surface search range. The green mass has the lowest factor of safety, the other surfaces shown (gray lines) illustrate the wide variety of slip surface trials evaluated to find the surface with the lowest factor of safety.

Thousands of stability trials can quickly be performed using a Monte-Carlo approach. While this approach is different than using closed first-order secondmoment solutions, using the computer to perform trials using possible soil properties 
generates similar factor of safety distributions, provided enough trials are performed. For this example case 2,000 trials were performed. For each trial new soil properties were randomly generated for each soil layer in accordance with defined distributions of soil parameters. Key parameters for stability analysis are shear strength and unit weight. For each trial a factor of safety is calculated and saved. The results of all of the trials are binned to estimate a frequency distribution of factors of safety for the slope. The probability that the factor of safety is less than 1.0 is used as the probability that the levee will experience unsatisfactory performance due to slope instability.

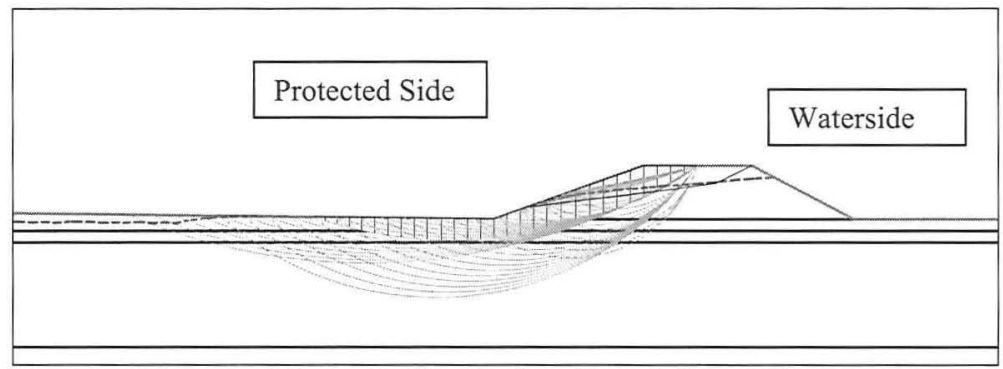

Figure 3. Slip Surface Search Illustration

Each potential slope stability failure mode of concern (ie landside steady state seepage, rapid drawdown, etc) is evaluated in this manner for a wide range of water loading levels to develop curves that relate the performance to the water loading. For practicality, pore pressures used in the slope stability analysis are based on best estimated steady state seepage conditions for the given water load. An example how stability and seepage failure modes are combined to a single function are presented in the Combining Seepage and Stability Section of this paper.

\section{Seepage}

The probability of unsatisfactory performance was defined as the probability that a critical seepage gradient was exceeded. Variables important to the seepage analysis included horizontal hydraulic conductivity, horizontal to vertical hydraulic conductivity, layering and layer dimensions, as appropriate. In general high seepage gradients were calculated when there were high contrasts in permeability between two layers (such as a low permeability layer over a high permeability layer). In general hydraulic conductivities were assumed to range over several orders of magnitude.

Seepage calculations were performed using steady-state assumptions and the computer program Seep/W by Geo-Slope International, Inc. Seepage trials were performed with all variables set at the expected values, except one which was varied between plus-one and minus-one standard deviation. The seepage gradients were tabulated and combined using a first-order second-moment solution and an assumed lognormal statistical distribution. A log-normal distribution was judged appropriate due to the wide variability in material properties. As typical seepage gradient contour plot is shown on Figure 4. 


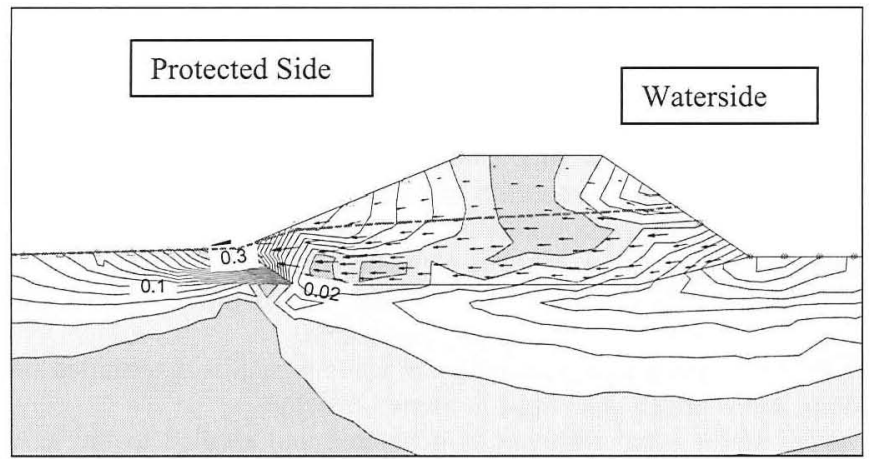

Figure 4. Example Vertical Seepage Gradients and Seepage Vectors

\section{Combining Seepage and Stability}

The combined probability of unsatisfactory performance is a combination of individual failure mode probabilities that correspond to the loading that the project will experience. Typically these modes include through seepage, under seepage, drawdown stability and long-term stability. Taylor series formulation is used to determine the combined performance. Figure 5 illustrates the combination of performance functions. Figure 5 includes a with and without drawdown curve. In many cases a drawdown failure mode may not cause economic damages if the levee can be repaired before another high water event.

$P_{u}=1-\prod\left(1-P_{i}\right)$

$P i=$ the probability of unsatisfactory performance of each potential failure mode

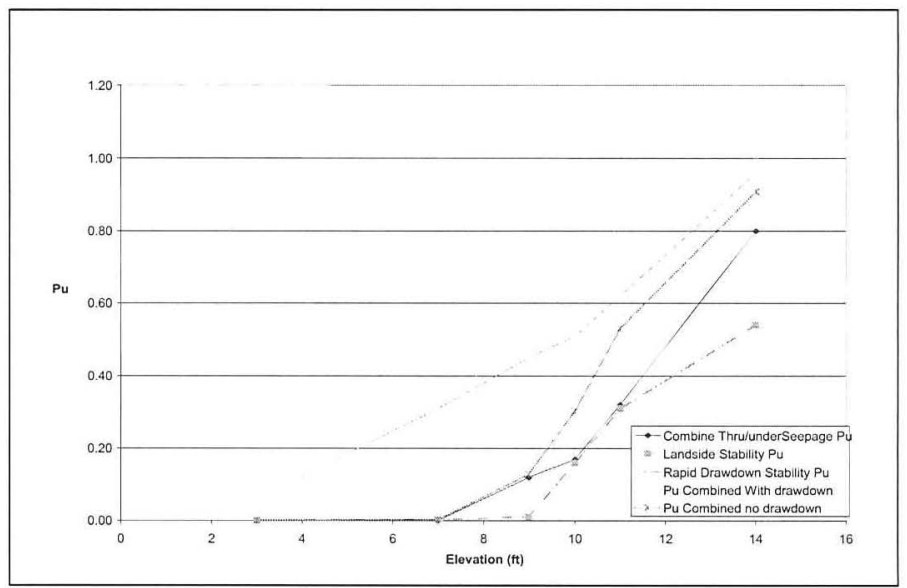

Figure 5. Example of Stability and Seepage Probability of Unsatisfactory Performance 


\section{LEVEE EROSION}

Army Corps of Engineers (Lee and Wibowo 2007) and European levee erosion models (Steenbergen et al., 2004; Buijs et al., 2004) use the limit state approach for estimating the probability of levee erosion-induced breaching. Soil erosion and breach parameters may be calculated using the $\operatorname{NRCS}(1997,2001)$ equations within a probabilistic framework. All equation variables are assigned a probability distribution function (typically a lognormal distribution). The expected value (mean) and standard deviation values generated are formulated as limit state functions in order to calculate a reliability index ( $\beta$ value). The probability of failure can be determined from the $\beta$ value within a standard normal distribution.

Figure 6 illustrates how probability of levee breach is determined for a given storm loading, and is briefly discussed in Steps 1-7 below.

1. A given storm event response is generated and applied to the levee. The flood impacts are then integrated over the storm event, beginning at a low water level and rising through the peak surge level at a time step of a tenth of an hour.

2. For each of the levee subsections the erosion analysis is applied, using a relative storm surge elevation, taking into account the time varying surge level and the local subsection levee crest.

3. Based on the generated storm event, wave runup is determined. From the wave runup data, the water level, wave height and wave period define the shear stress on the outer slope and the overtopping discharge.

4. Given the width of levee crest remaining and the shear stress applied by the hydraulic loading, a table look-up is performed within, which provides the outer slope erosion remaining width as a function of duration and shear stress. The table is interrogated by first interpolating to obtain for the current shear stress the equivalent duration of exposure that gives the current remaining crest width. Then the current time step in added to that equivalent duration and the incremental erosion determined by then re-interpolating the remaining crest width.

5. With the now updated remaining crest width and the current shear stress a look-up is performed which provides the critical time to breaching in hours. The impacts of overtopping erosion at the inside toe of the levee are estimated using critical time to breaching based on the remaining crest width and the current overtopping discharge.

6. The conditional probability of breaching is then determined from the critical time to breaching and the incremental duration (time step) by using tables. The steps 1-7 are repeated for each time step through the storm event, with the maximum probability of failure obtained during the storm.

7. The maximum probability of failure that is generated is tested by the Monte Carlo analysis for failure of the levee.

8. Length and temporal effects can be incorporated using Dutch methods, as appropriate (Vrouwenvelder et al. 2001). 


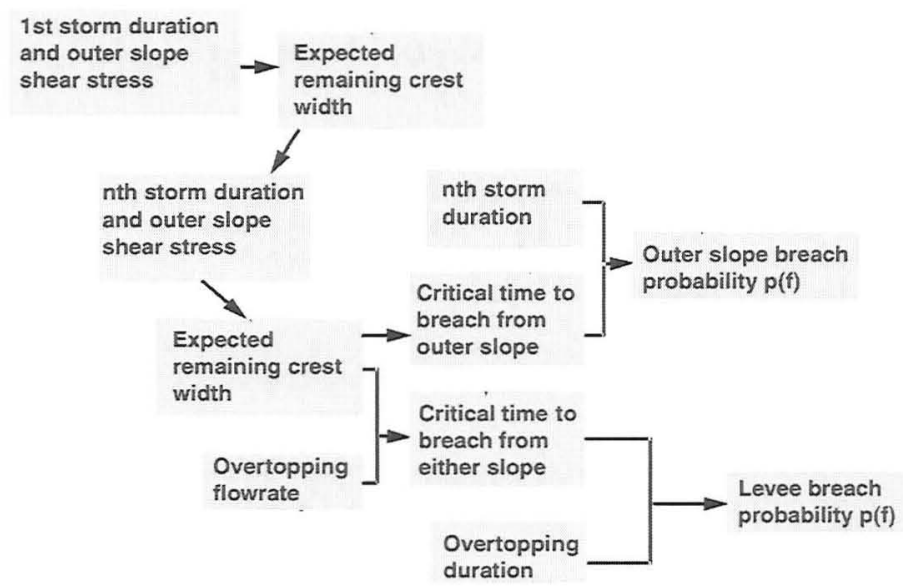

Figure 6. Process for Calculating Probability of Unsatisfactory Erosion Performance

\section{COMBINING $P_{U}$ FOR SLOPE STABILTY/SEEPAGE AND EROSION} FAILURE MODES

Combining the probabilities of failure in the Monte Carlo Analysis is performed by checking both the probability of unsatisfactory performance using stability and seepage failure modes, and using erosion failure modes for each storm trial. Flooding can be mapped when breaches occur using estimated breach dimensions.

For the stability and seepage failure modes, although an index point (weak link) is defined, flooding should be checked to see the sensitivity of the breach location. For the erosion failure modes, the randomness of the breach location is already incorporated into the hydrodynamic loading and erosion progression.

\section{APPLICATION AND CONSIDERATIONS}

Although calibration for this methodology is lacking in terms of both actual field performance and laboratory study, the methodology does provide a framework in which consistent decisions can be made regarding project economics (ie comparing different project alternatives to reduce flood damage for example).

Care should be taken by engineers when designing new structures not to design based solely on Probability of Unsatisfactory Performance. Appropriate proven design methods, associated uncertainties and risks, and appropriate redundancy designs should be incorporated in a complete flood protection design.

Future research in these subjects is warranted and needed, especially in light of new legislative requirements that will require engineering analysis in a holistic probabilistic framework. Particular areas of research may include:

- Incorporation of time and length effects in slope and seepage analysis.

- Developing a standard definition of Unsatisfactory Performance in terms of levee failure. 
- Incorporation of geotechnical spatial variation

- Calibrating failures to field performance in stability, seepage, and erosion modes

\section{REFERENCES}

Buijs, F.A., van Gelder, H.A.J.M., and Hall, J.W. (2004). "Application of reliability-based flood defence design in the UK," HERON, Vol 49, Issue 1, Delft University of Technology, Delft, The Netherlands. http://www. mechanics.citg.tudelft.nl/heron/2004 1/2004 1.html

Christian, John T., Ladd, Charles C., Baecher, Gregory B., (1994), "Reliability Applied to Slope Stability Analysis," Journal of Geotechnical Engineering Vol. 120, No 12 pp. 2180-2207.

Duncan, Michael, J. (2000), "Factors of Safety and Reliability in Geotechnical Engineering," Journal of Geotechnical and Geoenvironmental Engineering, Vol. 126 Issue 4, pp. 307-315.

Interagency Levee Policy Review Committee under contract to FEMA (2006), "The National Levee Challenge, Levees and the FEMA Flood Map Modernization Initiative, " Contract HSFEQ-04-DoO25.

Lee, L.T. and Wibowo, J.L. (2007). "Overtopped levee erosion toolbox: Risk assessment methodology and user's guide”, Draft Technical Report (in progress), ERDC Geotechnical and Structures Laboratory, Vicksburg, MS.

NRCS (1997). Chapter 51, Earth spillway erosion model, in USDA National Engineering Handbook, Part 628 Dams

NRCS (2001). Chapter 52, Field procedures guide for the headcut erodibility index, in USDA National Engineering Handbook, Part 628 Dams

Steenbergen, H.M.G.M., Lassing, B.L., Vrouwenvelder, A.C.W.M., and Waarts, P.H. (2004). "Reliability analysis of flood defence systems," HERON, Vol 29, Issue 1, Technische Universiteit Delft, Netherlands. http://www.mechanics.citg.tudelft.nl/heron/2004 1/2004 1.html

USACE (2007). "Certification of levee systems for the National Flood Insurance Program," Draft ETL 1110-2-570, U.S. Army Corps of Engineers, Washington, D.C.

USACE (1999). "Evaluating the reliability of existing levees," Appendix B, ETL 1110-2-556, 28 May, U.S. Army Corps of Engineers, Washington, D.C.

USACE(2006), "Risk Analysis for Flood Damage Reduction Studies, “Engineering Regulation 1105-2-101, U.S. Army Corps of Engineers, Washington. D.C.

Vrouwenvelder, A.C.W.M., Steenbergen, H.M.G.M., and Slijkhuis, K.A.H. (2001). "Theory manual of PC-RING", TNO Building and Construction Research, Delft, The Netherlands.

Wolff, Thomas, F., (1994), "Evaluating the reliability of Existing Levees, Report of Research Project: Reliability of Existing Levees," prepared for US Army Engineer Waterways Experiment Station 